Research Article

\title{
Financial Aberrations of Rural Customers of Business Correspondents: Characteristics, Cases and Curative Strategies
}

\author{
Samirendra Nath Dhar ${ }^{1}$, Pintu Prasad Jaiswal ${ }^{2 *}$
}

${ }^{1}$ Department of Commerce, North Bengal University, Dist.: Darjeeling, West Bengal-734013, India. E-mail dharsnd@gmail.com ${ }^{2}$ KGT Mahavidyalaya, Bagdogra, Dist.: Darjeeling, West Bengal - 734014, India. E-mail - ppjaiswal02@gmail.com

\section{Article Information} \\ Received: 23 April 2021 \\ Revised version received: 10 July 2021 \\ Accepted: 13 July 2021 \\ Published: 29 July 2021

\section{Cite this article as:} \\ S.N. Dhar and P.P. Jaiswal (2021) Int. J. Soc. Sc. \\ Manage. 8(3): 401-407. \\ DOI: 10.3126/ijssm.v8i3.38425

\section{*Corresponding author} \\ Pintu Prasad Jaiswal, \\ KGT Mahavidyalaya, Bagdogra, Dist.: Darjeeling, \\ West Bengal - 734014, India \\ Email:ppjaiswal02@gmail.com \\ Peer reviewed under authority of IJSSM \\ (C) 2021 IJSSM, Permits unrestricted use under the \\ CC-By-NC license.

\section{OPEN CACCESS} \\ This is an open access article \& it is licensed under a \\ Creative Commons Attribution Non-Commercial 4.0 \\ International \\ (https://creativecommons.org/licenses/by-nc/4.0/)
}

\begin{abstract}
Financial Inclusion through Business Correspondents is not free from financial aberrations. On the basis of some cases the paper investigated into the types and frequency of the financial aberrations, which are incident on customers .The magnitude of shocks as perceived by the $\mathrm{BC}$ customers due to the financial process aberrations and irregularities were gauged on a Likert scale and was found to be significantly high. As these shocks have a bearing on financial resilience, the research further attempted to investigate whether awareness of dealing with the system and thereby increasing financial resilience could be developed through financial literacy programs. A longitudinal research design was adopted and 17$18 \%$ of the male and female respondents from each district were exposed to a financial literacy programme in this context as devised by the researchers. It was found that the administration of the program on poor BC customers had a significant positive effect on their awareness and therefore on their build-up of financial resilience.
\end{abstract}

\section{Financial Aberrations and Business \\ Correspondents}

One of the key strategies for financial inclusion in India has been the introduction of the Business Correspondents model to deliver financial services as a low-cost alternative channel to branch-based banking for people with a low income and deprived sections dwelling in the far-flung rural areas. The model not only aims to provide an alternative banking channel to millions by making financial services accessible for the un-/under-banked population through a branchless banking facility but also supports the national agenda for employment generation (RBI, 2008). In India where less than $15 \%$ of villages have a brick-and-mortar bank branch, $\mathrm{BC}$ agents are the sole transaction outlet in thousands of villages. 
Business Correspondents (BCs) have augmented their outreach in thousands of unbanked villages, thereby providing easy access to banking services near the doorstep of the rural population who were previously bereft of formal financial system facilities. As reported by Reserve Bank of India, from a mere 34,621 Business Correspondent Agents (BCAs) in India in 2010, the number of BCAs has grown to more than 12 lakhs in 2020. However, no such system is without drawbacks. Jaiswal and Dhar (2019) have found through interviews, group discussions and case studies that there are aberrations in the appointment and operational procedures and need resolution.

In the Business Correspondent model there is outsourcing and reassigning of financial transactions from a bank, which is a regulated entity, to Corporate BCs and their BC agents. Dhar and Jaiswal (2020) reported that besides providing "deposit and withdrawal facilities for customers, BC agents also collect and make preliminary processing of loan applications, create awareness about savings and other products, disburse small value credit, help in post- sanction monitoring and follow-up recovery, receives and deliver small value remittances/other payment instruments. This means that a large variety of transactions are outsourced to the $\mathrm{BC}$ agents.

The prime concern here is that such outsourcing by banks, as perceived in these systems, has the chance to shift risk to customers, which are often beyond the ambit and control of mainstream bankers. Mohammad (2015) pointed out that low customer awareness, remote transactions in the absence of customers were the key risks in these systems to monitor transactions on real time basis.

Therefore, there remains a possibility that some grey sides may undermine the desired contribution of the $\mathrm{BC}$ model for financial inclusion and access and therefore needs to be investigated. Irregularities in financial transactions particularly with the rural customers with low literacy and financial literacy are not uncommon and have attracted the attention of researchers. According to Mudiri (2018) "Financial Services Fraud is commonly understood as dishonesty calculated for advantage - a deception deliberately practiced securing unfair or unlawful gain." Mehrotra et al. (2018) reported that "about $22 \%$ of agents in India faced fraud in the past one year. This is a significant jump from $2 \%$ reported in 2015 . The increase in fraud might be directly related to the many-fold increase in accountrelated transactions." The authors further reported that "the incidence of fraud is higher (29\%) among high-performing agents compared to others (18\%). This is probably because they conduct more transactions." Genega, Kairie and Bersudskaya (2015), opined that "fraud risk is often included separately in risk management frameworks owing to customers' sensitivity to fraud and the cost of fraud to the business. Fraud can target the agent, the customers, and the provider.

It must be comprehended that customers of BCs provide critical float and cash to the Business Correspondent system. These are the attributes that drive liquidity and deposit and credit transactions in the $\mathrm{BC}$ model of financial inclusion. . A high level of aberration in the system will discourage customers of $\mathrm{BCs}$ from investing in float and cash for fear of loss.

Moreover, economic conditions and financial resources of the rural folk are at a low level, resulting in financial shocks in the form of loss of pecuniary resources. Recovery from these shocks is not always easy as the livelihood activities that they pursue are often insufficient to generate surplus for savings.

This challenge is of a much larger dimension for the rural poor because the abilities for processing of information and adopting them, self-organization and learning from the financial environment is much lower than their urban counterparts. Comprehending the problems of the beneficiaries in this context builds up their Financial Resilience. Akter and Mallick, (2013) opined that the "process-orientated frameworks pose a challenge in terms of operationalising the definition of resilience as they define resilience as a dynamic concept." Knowledge of handling financial products can be built up through financial literacy programmes and experience of the beneficiaries can be built up when they handle the products and the systems based on their level of financial literacy. Some researchers like Hassan et.al (2018) believe that enhanced access to formal financial services can rally round people to turn out to be more financially resilient. Hussain et.al (2019) confirmed that "respondents with financial accounts are more resilient than those without accounts. The chances of being financially resilient are around 1.4 times higher for the account holders than their counterparts." Salignac et.al (2019) view resilience as how people bounce back from adverse financial events and the resources and support, they draw on.

\section{The Research Gap, Objectives and Methodology of the Study}

Despite the gravity of the problem, very scanty research has been undertaken to study the nature of financial aberrations faced by the customers of the BCs. Mudiri (2018) listed some types of methods as to how agents defraud banking customers. Similarly, PWC (2015) stated that many customers are overcharged and in some cases the customers make deposit but is not reflected in their account. However, a listing of these methods without being backed by empirical evidence fails to give a comprehensive idea about the extent of these financial aberrations being committed. Hence a large research gap exists as to what is the nature, 
type and extent of financial aberrations incident on customers of BCs and what strategies could be taken to build up their financial resilience.

To fill up these gaps the objectives of this research was to identify:

(i) What were the most common types of aberrations or which of the aberrations occurred with a higher frequency?

(ii) What was the magnitude of shocks faced by the customers when subject to these financial irregularities?

(iii) Could resilience be built up among the customers of BCs by increasing awareness about the processes of dealing with $\mathrm{BC}$ through some form of financial literacy programme?

The methodology adopted to find answers to these questions involved individual and focus group interviews which were carried out with individuals in different villages of four districts of West Bengal and initial cases were formulated. These cases were described in other villages to find out similar experiences and then a questionnaire was structured based on the cases and shared experiences and then self- administered to 700 respondents in different rural areas in the aforesaid district of North Bengal. Out of the total questionnaires administered, the response rate was $82 \%$. Hence the sample respondents stood at 574. The sample distribution is given in Table 1.

\section{Findings of the Study}

In an attempt to find answers to the first question, i.e. the types of financial aberrations that had emanated from dealing with $\mathrm{BCs}$, the following cases have been briefly described below. Names of respondents have been changed to maintain secrecy.

\section{Illustrative Cases of the Variety of Financial Aberrations}

\section{Non-Issuance of Transaction Slip}

Rahim, a tea garden worker, prefers to withdraw money from the nearby Customer Service Point (CSP). After giving the biometric, the $\mathrm{BC}$ hands over the cash to him and convey him the available balance. Rahim leaves the counter without demanding and verifying the available balance in the account through the transaction slip. This is the overall trend followed by the majority of customers resulting in blind trust and faith which turns costly in the future.

\section{Fraudulent call}

Karim, a carpenter resides in a village having a population of 1500 . He recently opened a bank account with SBI BC. After two weeks, the BC hands over Debit cum ATM Card and generated PIN using his biometric. Later, he received a call from an unknown number enquiring about ATM PIN and non-compliance of $\mathrm{KYC}$, he shares all the information sought by the person on the call after which the entire amount was siphoned from his account.

\section{Unauthorized activation of APY \& PMJJBY scheme}

Rathin, a plumber, age 35 years deposits his savings in the bank account opened at the CSP in his village. One day while checking his balance through a mini statement, he finds that some balance amount has been deducted from his account. When enquired with BC, it was found that APY and PMJJBY were activated without taking his consent. Many BC conveys to the customers that they are assigned a target by Corporate BC which is fulfilled by them without taking the customers' consent on many occasions.

\section{Adding unauthorized beneficiary in a customer account}

Sahil has been frequently depositing money in his account and does a regular transaction like withdrawal and remittance to his parents' account residing in a rural village. He maintains an average balance of Rs.20,000 to 30,000 in his account. One day, he goes to the other village CSP and requests to withdraw some balance, but to his surprise he finds his money missing from the account. Thereafter, he informs the customers $\mathrm{BC}$ about the problems to which his $\mathrm{BC}$ responds that there was a technical error due to which the money was transferred to the wrong account.

\section{Issuing fake fixed deposit receipt and granting a loan} Amina applied for a loan with the local BC after hearing about it from other villagers. She received the loan at a higher interest rate. Every month she deposits a fixed amount and signed it in the register maintained by the BC. It was during her visit to the link branch; the matter came to the limelight of the branch manager about the unauthorised collection. Further, he was also collecting the FD amount from its customer by issuing a fake deposit receipt. Later, the bank informs the Corporate BC and suspend him from carrying on the activities.

Table 1: District- Wise Sample Distribution

\begin{tabular}{|l|l|l|l|l|l|}
\hline Sample Sex & Darjeeling District & Kalimpong District & Jalpaiguri District & Coochbehar District & Total \\
\hline Male & 75 & 41 & 84 & 60 & 260 \\
\hline Female & 92 & 58 & 93 & 71 & 314 \\
\hline Total & 167 & 99 & 177 & 131 & 574 \\
\hline
\end{tabular}




\section{Unauthorized charges on withdrawal}

Kunal, a daily wage worker has an account with the BC. He does the transaction with the agent during the evening time after coming back from his work. But on the day of weekly haat, when he withdraw money after $5 \mathrm{pm}$ the BC charges extra money citing additional cost required for conveyance. Even, Kunal pays extra charges while getting withdrawal during haat.

\section{Charges for printing passbook}

Babon has an account with the $\mathrm{BC}$ in a rural village. The distance of the link branch is $11 \mathrm{~km}$ from the $\mathrm{BC}$ point. Every fortnight, Babon and other customers deposit their passbook with the BC for updating it from the link branch. Each customer is charged with a fixed amount as a part of traveling expenses by the $\mathrm{BC}$ which is collected while handing over the passbook to them.

\section{Using customer money for BCs own business}

Shyamol runs a grocery shop in a rural village. Whenever he has surplus cash he hands over the cash to the $\mathrm{BC}$ and asks him to transfer to his account. Many other villagers follow the same path of handing over the cash since biometric is not required for depositing money in their account. Here, the BC cleverly uses the customer money for giving withdrawal throughout the day and deposit the money to their account once they have sufficient cash in their hand. Even if the customer visits the CSP and enquires about their deposit, he simply tells them that there was a link failure due to which the transaction was delayed.

\section{Unauthorized access to Debit Card PIN}

Souvik, a tea garden worker had opened an account with the nearby $\mathrm{BC}$ in his village. Later, the Debit card is sent to the link branch to be handed over to the $\mathrm{BC}$. When he visits the CSP, the BC informs him about the debit card wherein Souvik along with the majority of the villagers who are illiterate ask the BC to generate their PIN. Many of the customers are duped by the BC using their debit card PIN which is supposed to be confidential.

Further, it cannot be claimed that the types of financial aberrations identified are exhaustive, however even if these types are illustrative, they carry enough importance to be explored in terms of their outreach and frequency. The next subsection deals with this.

\section{The Frequency of the Types of Financial Aberrations:}

Based on the observed cases, the study further attempted to gauge the frequency of the variety of financial aberrations incident on the sample customers of the BCs. This was done by administering the questionnaire to the sample respondents and asking them on a dichotomous (Yes, No) scale whether they were subject to any of these financial aberrations any time after becoming customers of BC. The results are shown in the Table 2.

Though the Table 2 shows the percentage of respondents affected by the financial aberrations are varied, yet keeping in consonance with the findings of the case studies, the empirical evidence shows that the customers have been inflicted by all the types of financial aberrations identified earlier.

\section{The Magnitude of Financial Shocks Perceived by Customers Due to Different Types of Financial Aberrations:}

In this section, attempts have been made to find the level of financial shock felt by the customers who were subject to a different type of financial aberrations. It is deemed that higher the magnitude of financial shock felt by the customers, more would be the adverse effect on their financial resilience. The magnitude of these shocks have been attempted to be measured on a Likert's five-point scale with the following anchors: - Very High (2), High (1), Do not know (0), Low (-1), Very Low (-2).

Table 2: The Frequency of Financial Aberrations

\begin{tabular}{lll}
\hline Type of Financial Aberrations & Total Customers affected (N) & Total (\%) \\
\hline Non-Issuance of Transaction Slip & 286 & 49.82 \\
Fraudulent Call & 60 & 10.45 \\
Unauthorized activation of APY \& PMJBY scheme & 145 & 25.26 \\
Adding unauthorized beneficiary & 31 & 5.40 \\
Issuing fake fixed deposit receipts and granting loans & 52 & 8.09 \\
Unauthorised charges on withdrawal & 223 & 38.85 \\
Charges for printing passbooks & 100 & 17.42 \\
Using Customers' money for BC own business & 149 & 25.95 \\
Unauthorised creation and access to debit card pin & 130 & 22.64
\end{tabular}

Source: Field Survey 
Table 3: Magnitude of Financial Aberrations Shocks perceived by Customers

\begin{tabular}{|c|c|c|c|c|c|c|c|c|c|c|}
\hline $\begin{array}{l}\text { SI } \\
\text { No. }\end{array}$ & Types & $\mathbf{N}$ & $\begin{array}{l}\text { Very } \\
\text { High } \\
(+2)\end{array}$ & $\begin{array}{l}\text { High } \\
(+1)\end{array}$ & $\begin{array}{l}\text { Do not } \\
\text { Know (0) }\end{array}$ & $\begin{array}{l}\text { Low } \\
(-1)\end{array}$ & $\begin{array}{l}\text { Very } \\
\text { Low } \\
(-2)\end{array}$ & Mean & SD & $\mathbf{Z}$ \\
\hline 1 & $\begin{array}{l}\text { Non-Issuance of Transaction } \\
\text { Slip }\end{array}$ & 286 & 71 & 95 & 78 & 28 & 14 & 0.63 & 0.01 & $2.96 *$ \\
\hline 2 & Fraudulent call & 60 & 47 & 11 & 2 & 0 & 0 & 1.75 & 0.08 & $2.63 *$ \\
\hline 3 & $\begin{array}{l}\text { Unauthorised activation of } \\
\text { APY \& PMJJBY scheme }\end{array}$ & 145 & 83 & 41 & 11 & 7 & 3 & 1.33 & 0.03 & $2.89 *$ \\
\hline 4 & $\begin{array}{l}\text { Adding unauthorized } \\
\text { beneficiary }\end{array}$ & 31 & 11 & 5 & 7 & 5 & 3 & 0.52 & 0.11 & 1.88 \\
\hline 5 & $\begin{array}{l}\text { Issuing fake fixed deposit } \\
\text { receipt and granting a loan }\end{array}$ & 52 & 21 & 18 & 7 & 5 & 1 & 1.02 & 0.06 & $2.28 * *$ \\
\hline 6 & $\begin{array}{l}\text { Unauthorised charges on } \\
\text { withdrawal }\end{array}$ & 223 & 99 & 85 & 11 & 20 & 8 & 1.11 & 0.02 & $2.92 *$ \\
\hline 7 & $\begin{array}{l}\text { Charges for printing } \\
\text { passbook }\end{array}$ & 100 & 21 & 49 & 14 & 13 & 3 & 0.72 & 0.04 & $1.98 *$ \\
\hline 8 & $\begin{array}{l}\text { Using customers money for } \\
\text { BCAs own business }\end{array}$ & 129 & 18 & 21 & 31 & 41 & 18 & 0.69 & 0.03 & 1.79 \\
\hline 9 & $\begin{array}{l}\text { Unauthorised creation and } \\
\text { access to Debit Card PIN }\end{array}$ & 130 & 79 & 24 & 8 & 7 & 12 & 1.16 & 0.05 & $2.02 * *$ \\
\hline
\end{tabular}

Source: Field Study; Note: * denotes significance at $1 \%$ level and ** at 5\% levels

The mean scores have been calculated and the following null hypothesis has been made:

$H_{0}$ : The perception of magnitude of shocks of different types of financial aberrations by the customers would be low i.e. $\bar{X}<0$

$H_{1}$ : The perception of magnitude of shocks of different types of financials aberrations by the customers would be high i.e. $\bar{X}>0$

The Table 3 shows that the null hypothesis has been rejected in seven out of nine cases of financial aberrations. This signifies that in most cases of financial aberrations, the customers perceive it of high or higher magnitude and therefore have an effect on their financial resilience.

On interviewing the customers further, it was found that most of them were not aware earlier that these financial aberrations could be resisted if they were aware of how the BC system operates and what precautions they could take so that their process-based financial resilience could be improved.

\section{The Curative Strategies: Administering Financial Literacy Programmes to the Customers}

Drawing lessons from the above findings it was next decided to administer financial literacy programmes to the customers and see whether there was any improvement in their awareness levels after being administered the programme. For this purpose, it was decided to work with 100 customers whose response was earlier obtained for the earlier sections of this study. Accordingly, $17 \%$ to $18 \%$ of the male and female respondents from each district were selected on a convenience basis. This method was adopted as there were severe constraints of cost and access to the respondents. A longitudinal research design was adopted and the same questionnaire was administered just before conducting the financial literacy programme and after a month of administering the programme.

The items in the table reflect the themes on which the financial literacy programme on dealing with financial aberrations was conducted. A five-point Likert scale was used with the following anchors: Fully Aware - FA (2), Somewhat Aware-SWA (1), No Response -NR (0), Somewhat Unaware - SWUA (-1) and Totally UnawareTUA (-2). The reliability score of this scale based on the calculated value of Chronbach's Alpha is 0.7452 .

The following hypotheses were constructed based on the scores obtained from the beneficiaries before administering the financial literacy programmes and after administering the financial literacy programme.

$H_{0}$ : The awareness levels of customers about financial aberrations would not change after administration of the financial literacy programmes, i.e the mean awareness scores of the respondents before and after the literacy programme would be the same,

Or $\bar{X} a=\bar{X} b$

$H_{1}$ : The awareness levels of customers about financial aberrations would be higher after administration of the financial literacy programmes, i.e the mean awareness scores of the respondents after the literacy programme would be higher.

Or $\bar{X} a>\bar{X} b$

The results of the test of difference of means are shown in the Table 4 
Table 4: Differences of Awareness Scores Before and After administering Financial Literacy Programme

\begin{tabular}{|c|c|c|c|c|c|c|}
\hline \multirow[t]{2}{*}{ S.N. } & \multirow[t]{2}{*}{ Statement } & \multicolumn{2}{|c|}{ Mean Score } & \multirow{2}{*}{$\begin{array}{l}\text { Difference of } \\
\text { Mean Score } \\
(\overline{\mathbf{X}} \mathbf{a}-\overline{\mathbf{X}} \mathbf{b})\end{array}$} & \multirow[t]{2}{*}{ S.E. } & \multirow[t]{2}{*}{ Z Score } \\
\hline & & $\begin{array}{l}\text { After } \\
(\overline{\mathbf{X}} \mathbf{a})\end{array}$ & $\begin{array}{l}\text { Before } \\
(\overline{\mathbf{X}} \mathbf{b})\end{array}$ & & & \\
\hline (i) & Not responding to call seeking account details & 1.74 & 0.59 & 1.15 & 0.031 & $37.09 *$ \\
\hline (ii) & Avoid Clicking unknown link messages & 1.44 & 0.79 & 0.65 & 0.031 & $20.96^{*}$ \\
\hline (iii) & $\begin{array}{l}\text { Generating PIN through messages or ATM } \\
\text { personally }\end{array}$ & 1.31 & 0.24 & 1.07 & 0.026 & $41.15^{*}$ \\
\hline (iv) & $\begin{array}{l}\text { Not sharing ATM card details and PIN and storing it } \\
\text { secretly }\end{array}$ & 1.91 & 0.73 & 1.18 & 0.032 & $36.87^{*}$ \\
\hline (v) & $\begin{array}{l}\text { Demanding transaction slip after every biometric } \\
\text { fingerprint and reading it carefully }\end{array}$ & 1.76 & 0.75 & 1.01 & 0.032 & $31.56^{*}$ \\
\hline (vi) & Updating Passbook and going through it regularly & 1.4 & 0.11 & 1.29 & 0.01 & $129 *$ \\
\hline (vii) & $\begin{array}{l}\text { Sharing any fraud or cheating committed with them } \\
\text { to other friends }\end{array}$ & 1.1 & 0.78 & 0.32 & 0.03 & $10.66^{*}$ \\
\hline (viii) & $\begin{array}{l}\text { Complaining to bank official if any extra money is } \\
\text { charged or demanded by the BCs }\end{array}$ & 1.41 & 0.37 & 1.04 & 0.028 & $37.14^{*}$ \\
\hline (ix) & $\begin{array}{l}\text { Putting signature and date or thumb impression } \\
\text { whenever any official documents photocopy is } \\
\text { sought by the BCA }\end{array}$ & 1.17 & 0.19 & 0.98 & 0.026 & $37.69 *$ \\
\hline$(\mathrm{x})$ & $\begin{array}{l}\text { Knowing about the charges levied on different } \\
\text { products and services }\end{array}$ & 1.53 & 0.49 & 1.04 & 0.029 & $35.86^{*}$ \\
\hline (xi) & Counting cash properly before leaving the counter & 1.71 & 1.26 & 0.45 & 0.034 & $13.23^{*}$ \\
\hline
\end{tabular}

\section{Conclusions and Policy Implications}

The findings of the study reveal that rural people who have been financially included in the formal system and have access to the system through Business Correspondents are not free from financial shocks caused by financial aberrations. Financial shocks in various degrees of magnitude do have a telling effect on their financial resilience. Belayeth Hussain et al. (2019) view of increasing financial resilience through financial inclusion draws no contradiction in this study, but a supplementary to his findings is that inclusion in the system has to be based on building awareness about the process aberrations that have a probability of occurrences. In this context views expressed by Cutter et al. (2008) regarding the process-based approach of resilience being "more extensive than just recovery from current hazards" but also "its capacity to reduce exposure to hazards in general," has to be regarded with much significance. Capacity to deal with financial aberrations and frauds can be developed through financial literacy programmes and which in turn can build up sustainable financial resilience of the rural folk who are financially included through agency banking systems. If confidence and awareness about financial aberrations is instilled into these people through financial literacy programmes, the demand for the BC model will not be weakened and therefore lead to sustainability of this model.

\section{Acknowledgement}

The authors wish to extend gratitude to Bank Manager, Corporate BCs official and BCs for their co-operation during the field survey.

\section{References}

Akter S, and Mallick B (2013) The Poverty-VulnerabilityResilience Nexus: Evidence from Bangladesh. Ecological Economics 96:114-124.

Belayeth Hussain AHM, Endut N, Das S, Chowdhury MTA, Haque N, Sultana S and Ahmed J (2019) Does financial Inclusion increase Financial Resilience? Evidence from Bangladesh. Development in Practice 1-10. DOI: 10.1080/09614524.2019.1607256

Cutter SL, Barnes L, Berry M, Burton C, Evans E, Tate E and Webb J (2008) A Place-based Model for Understanding Community Resilience to Natural Disasters. Global Environmental Change 18(4): 598-606.

Dhar SN and Jaiswal PP (2020) Liquidity Balancing and Transaction Denial Imbroglios of Business Correspondents: An Investigation using Structured Equation Modelling. Indian Accounting Review 24(2): 2144.

Genga K, Kiarie W and Bersudskaya V (2018) Measuring Risk in Agent Networks -What Risks Are Inherent in Agency Business and How to Track Them. Microsave-Helix 


Institute of Digital Finance

http://www.microsave.net/files/pdf/Measuring_Risk_in Agent_Networks.pdf

Hassan NM, Kassim ES and Ma'on, S.N., (2018). Factors Influencing Individual Financial Resilience in facing Economic Crisis: Does Financial Literacy really help? International Journal of Academic Research in Business and Social Sciences 8(11): 1613-1623. DOI:10.6007/IJARBSS/v8-i11/5284

Jaiswal PP and Dhar SN (2019) Business Correspondent Agents for Promoting Financial Inclusion: A Study of Glitches and Gaps in Appointment and Operations. International Journal of Research and Analytical Reviews 6(2): 566576.

Mehrotra A, Tiwari A, Karthick MP, Khanna M and Khanna V (2018) State of the Agent Network, India 2017. Agent Network Accelerator Research India Country Report. http://www.microsave.net/wpcontent/uploads/2018/12/A gent_Network_Accelerator_Research_Country_Report_I $\underline{\text { ndia.pdf }}$

Mohammad GA (2015) Mitigation of Consumer Risks in Digital Financial Services -Perspective from Indonesia \& Beyond presented at the International Telecommunication Union
(ITU) workshop on "Digital Financial Services and Financial Inclusion" in Geneva, Switzerland on 14-15 December 2015

https://www.microsave.net/2017/01/16/mitigation-ofconsumer-risks

Mudiri J L (2018) Fraud in Mobile Financial Service, Microsave Publications.

https://www.microsave.net/2012/11/26/fraud-in-mobilefinancial-services/

PWC (2015). Compilation of Drill down Case Studies of Existing Business Correspondents and Business Correspondent (BC) Model in MP https://www.sidbi.in/files/article/articlefiles/SIDBIUpdated\%20Draft\%20Report-MP- BC\%20Study-.pdf

RBI (2008) Financial Inclusion. Report on Currency and Finance https://www.rbi.org.in/scripts/PublicationsView.aspx?id= $\underline{10494}$

Salignac F, Marjolin A, Reeve R and Muir K (2019) Conceptualizing and Measuring Financial Resilience: A Multidimensional Framework. Social Indicators Research: An International and Interdisciplinary Journal for Quality-of-Life Measurement 145(1): 17-38. 